\title{
Tecnologias de Informação e Comunicação na Educação de Jovens e Adultos: A Expectativa Discente
}

\author{
Rafael Castro de Souza ${ }^{1}$, Oldênia Fonseca Guerra², Regina Celi Alvarenga de \\ Moura Castro ${ }^{3}$ \\ ${ }^{1}$ Instituto Federal de Educação, Ciência e Tecnologia do Rio Grande do Norte (IFRN) - \\ Campus Avançado Parelhas, Parelhas - RN - Brasil \\ ${ }^{2}$ Universidade Federal do Piauí (UFPI) - Colégio Técnico de Bom Jesus (CTBJ), \\ Bom Jesus - PI - Brasil. \\ ${ }^{3}$ Universidade Federal do Pará (UFPA) - Campus Universitário de Altamira, \\ Altamira - PA - Brasil \\ rafael.castro@ifrn.edu.br, oldenia@ufpi.edu.br, reginalmm@yahoo.com.br
}

\begin{abstract}
This article analyzes student expectations regarding the use of Information and Communication Technologies as teaching and learning tools in Youth and Adult Education (YAE). For this, we tried to analyze the technological mastery of the students, the expectation and awareness of the possibilities arising from the use of technologies in teaching and the frequency of how the use of these technologies in practice by YAE teachers has occurred. As a methodological procedure to assess the degree of agreement of the respondents' answers, the Likert scale was used in a five-point model. Given the results obtained, it is possible to verify notes by the students that indicate prior knowledge, acceptance and good expectations about the use of ICT in teaching.
\end{abstract}

Resumo. Este estudo analisa a expectativa discente em relação ao uso das Tecnologias de Informação e Comunicação como ferramentas de ensino e aprendizagem na Educação de Jovens e Adultos (EJA). Para isso, procurouse analisar o domínio tecnológico dos alunos, a expectativa e consciência das possibilidades decorrentes do uso das tecnologias no ensino e a frequência de como tem se dado o uso dessas tecnologias na prática pelos docentes da EJA. Como procedimento metodológico para avaliação do grau de concordância das respostas dos entrevistados, foi utilizado à escala Likert no modelo de cinco pontos. Diante dos resultados obtidos, pode-se verificar apontamentos por parte dos discentes que indicam conhecimento prévio, aceitação e boas expectativas sobre o uso das TIC no ensino.

\section{Introdução}

A inserção das Tecnologias da Comunicação e Informação (TIC) atuais nos mais diversos campos da sociedade, seja industrial, educacional, lazer, segurança, entre tantos outros, tem proporcionado uma mudança significativa no número de novas possibilidades e oportunidades, se comparadas ao século passado. No que tange a educação, as tecnologias têm contribuído para o auxílio dos professores, estudantes e 
gestores permitindo assim a realização de um novo conjunto de atividades didáticopedagógicas totalmente diferentes do que propõe o modelo tradicional de ensino.

Nesse sentido, devemos levar em consideração o trabalho do professor, pois este profissional da educação não se resume apenas a passar a instrução para o estudante, mas também em auxiliá-lo na construção do conhecimento e desenvolvimento das competências da inovação, adaptabilidade, criatividade, autonomia, comunicação e colaboração (MERCADO, 2002). Em relação às tecnologias na escola, cabe salientar que muito embora as escolas tenham recebido investimentos quanto a sua infraestrutura tecnológica, isto não necessariamente garante o uso desses recursos devido a própria resistência docente no uso das tecnologias no ensino (MIRANDA, 2016).

Assim sendo, em concordância com o exposto, devemos considerar a grande importância da integração tecnológica na sala de aula e qualificação docente para superação do modelo tradicional de ensino que ainda persiste em muitas escolas no Brasil. Dessa forma, com base na temática do uso das tecnologias no ensino e motivados por um estudo reflexivo, crítico e participativo, nesse artigo é apresentado resultado de um estudo de caso, realizado em uma escola pública do município da cidade de Bom Jesus, que teve como objetivo identificar a expectativa discente, na Educação de Jovens e Adultos, em relação ao uso das TIC na prática docente.

Este artigo está organizado além da Introdução e Considerações Finais, em seções. Na primeira Seção é realizada a fundamentação teórica que fundamentou a pesquisa, na segunda Seção são descritos os materiais e métodos que foram empregados para a coleta dos dados; e na Seção três são apresentados as discussões dos resultados obtidos.

\section{Referencial Teórico}

\subsection{Tecnologias de Informação e Comunicação}

É notório nos dias atuais que a tecnologia está inserida em diferentes campos de atuação, tais como na saúde, indústria, negócios, na educação, entre tantos outros. A aplicação das tecnologias na educação pode se dar de diferentes maneiras, que vão desde o auxílio na resolução de questões pelos estudantes, como também para proporcionar uma maior qualidade na exposição dos conteúdos por parte dos professores, confirmando que muitas são as possibilidades de utilização das TIC na prática pedagógica desenvolvida por professores, desde a educação infantil até o ensino superior.

As Tecnologias de Informação e Comunicação, também denominado de Novas Tecnologias de Informação e Comunicação (FLORES, 2018), podem ser definidas como sendo:

“[...] recursos tecnológicos que envolvem o uso de computador e redes telemáticas (Internet) que são o conjunto de processos e produtos derivados da informática, suportes de informação e canais de comunicação relacionados com o armazenamento, processamento, e transmissão digitalizada de informação (MERCADO,1999, p. 9)."

As TIC compreendem a informática, a microeletrônica e as telecomunicações como eixos básicos, esses eixos atuam não de forma isolada, mas interativamente para a configuração de novas realidades (HUNG, 2015). Basicamente, toda a infraestrutura 
tecnológica moderna possui como base as TIC, dessa forma, nos dias atuais está quase que inconcebível pensar o cotidiano sem algum tipo de interferência tecnológica.

Hoje em dia, até mesmo as atividades dos jovens de brincar, estudar, marcar encontros, namorar, entre tantas outras são já realizadas em um mundo virtual a partir da mediação das TIC com resultados no mundo real (VELOSO, 2017). No Brasil, a lei $\mathrm{n}^{\circ}$ 9.394, de 20 de dezembro de 1996 (BRASIL, 1996), que estabelece as diretrizes e bases da educação nacional, LDB 9.394/96 já contemplou, por meio das novas redações dadas, a inserção da tecnologia no ensino brasileiro.

Conforme MIRANDA (2016), a introdução dessas tecnologias no ensino modifica radicalmente a maneira da percepção do mundo e de si próprio, no qual, a partir dos novos formalismos para representação da informação mediantes os novos sistemas de informação, amplifica-se o desenvolvimento cognitivo. A exemplo, podemos citar a situação dos processadores de textos, se antes as crianças estavam apenas habituadas ao procedimento da escrita no papel, hoje, elas precisam não somente aprender o referido procedimento, como também, saber utilizar os processadores de textos, o que inclui o aprendizado de várias funções, simbologias e novas terminologias.

Há de se considerar ainda que a integração da tecnologia como prática docente tem se dado lentamente, isto se deve a múltiplas razões, dentre as quais podemos mencionar a falta de aptidão dos docentes no uso desses recursos tecnológicos, ou ainda a resistência em mudar a didática das aulas, situações essas que podem ser contornadas a partir da continuação à qualificação docente ao mesmo tempo em que se deve encorajar, no cotidiano da escola, o uso das novas tecnologias da comunicação e da informação, conforme consideram BARACHO e NÓBILE (2019).

A situação acima descrita por BARACHO e NÓBILE (2019) não reflete apenas a realidade brasileira, mas vai ao encontro da realidade também de outros países. Conforme pode ser visto em PERALTA e COSTA (2007), foi realizado um estudo acerca do uso das TIC por professores do ensino básico de Portugal, Espanha, Itália e Grécia, e ficou evidenciado em síntese que: i) As TIC não estavam ainda sendo integradas como recurso nas atividades de ensino; ii) Os professores usam as TIC sem a compreensão dos princípios de aprendizagem subjacentes; iii) Perdura-se uma ideia geral de que não há muitos professores que possuem o domínio ideal das TIC no ensino.

Reafirmamos, dessa forma, em consonância com o exposto, que se torna claro a importância de que as TIC façam parte do cotidiano no ensino escolar, pois com o auxílio delas se pode romper de maneira mais fácil o modelo tradicional de ensino, propiciando um ambiente muito mais interativo, atualizado e permissivo no que se refere à aplicação prática dos conhecimentos obtidos na disciplina por parte dos estudantes.

\subsection{Educação de Jovens e Adultos}

De acordo com a nova redação dada pela Lei $n^{\circ} 13.632$ de 2018, que alterou o artigo 37 da Lei 9.394 de 1996, diz que:

\footnotetext{
"A educação de jovens e adultos será destinada àqueles que não tiveram acesso ou continuidade de estudos nos ensinos fundamental e médio na idade própria e constituirá instrumento para a educação e a aprendizagem ao longo da vida (BRASIL, 2018, p. 1).”
} 
Compete ao Poder Público a viabilização e permanência desse público na escola, sendo o ensino articulado, preferencialmente, em conjunto com a educação profissional (BRASIL, 1996). Nesse sentido, é fundamental uma política pública voltada para esse público, visando assim sua escolarização, profissionalização e integração como cidadãos que por inúmeros motivos de ordem econômica, política, social e histórica, tiveram seus direitos de concluir a educação básica, restringidos (BRASIL, 2007). Todavia, como destaca BARACHO e NÓBILE (2019), muitas são as dificuldades que o educador enfrenta ao trabalhar com esse público, que inclui os desafios de ordem cultural, pedagógica, social, entre outros, que devem ser superadas pelos docentes e gestores. No que tange aos desafios de ordem pedagógica, podemos citar a avaliação da aprendizagem, que não deve possuir como fim o mero diagnóstico da situação aprovado ou reprovado, mas antes, a real possibilidade em estimular o desejo de aprender pelos estudantes.

Dentre as teorias pedagógicas discutidas por DA FONSECA (2019), a Pedagogia Libertadora vai ao encontro às necessidades e peculiaridades desse público, que se apoia nos postulados de Paulo Freire publicados nos seus livros Educação como Prática de Liberdade no ano de 1967 e Pedagogia do Oprimido no ano de 1968 (ALCOFORADO, BARBOSA e BARRETO, 2017). Onde Paulo Freire considera, em resumo, a valorização dos saberes prévios dos estudantes, ressignificação das atividades de ensino, desenvolvimento das habilidades de realização de atividades sociais, pessoais e profissionais para apresentar alterações, quando preciso, na qualidade de sua vida, de sua comunidade e da sociedade, objetivando assim a inserção desses estudantes no exercício da cidadania cívica e plena.

\section{Materiais e Métodos}

Diante da possibilidade de dar voz aos estudantes da EJA com base nos princípios expostos em FREIRE (2019), o objetivo deste trabalho consistiu em analisar a expectativa desse público em relação ao uso das TIC no seu processo de aprendizagem elucidando questões no que tangem: i) ao domínio tecnológico desses estudantes ; ii) à expectativa e consciência das possibilidades geradas no uso das tecnologias no ensino; iii) à frequência que tem se dado o uso dessas tecnologias pelos docentes.

Este trabalho possui a seguinte configuração de pesquisa: i) quanto ao objetivo de pesquisa é do tipo exploratório; ii) Quanto aos procedimentos técnicos foi utilizado a pesquisa bibliográfica para a devida fundamentação teórica do trabalho, e estudo de caso para a análise das instâncias visando o detalhamento da questão; iii) Quanto à sua natureza é do tipo quantitativa e qualitativa, e; iv) Quanto ao local de realização da pesquisa esta foi feita na Unidade Escolar Joaquim Rosal Sobrinho, que é uma escola pública na cidade de Bom Jesus-PI. Como instrumento de coleta de dados foi utilizado um questionário semiestruturado aplicado aos estudantes. A análise dos dados provenientes das questões objetivas foi realizada obedecendo os princípios da escala Likert, que é uma técnica psicométrica para avaliação de questionários sociais $\mathrm{e}$ educativos e que foi concebida para a realização da medição das atitudes, opiniões ou percepções das pessoas sobre determinado um assunto, quando o entrevistado opta por uma resposta dentre uma variedade de respostas (JOSHI et al., 2015), tendo sido o questionário feito com a configuração do modelo de cinco pontos. 


\section{Resultados e Análise dos Dados Obtidos}

Esta seção apresenta os resultados acerca da pesquisa de campo que foi realizada na Unidade Escolar Joaquim Rosal Sobrinho, na cidade de Bom Jesus-PI. Ao todo, participaram da pesquisa trinta e dois alunos da Educação de Jovens e Adultos que estavam divididos em quatro turmas diferentes.

O formulário de pesquisa possui quatro perguntas de caráter objetivo, objetivando a análise quantitativa, e uma pergunta de caráter subjetivo, objetivando a análise qualitativa, onde a fim de facilitar o entendimento optamos por dividir as informações de acordo com a natureza quantitativa e qualitativa dos dados, que serão expostos nas subseções a seguir.

\subsection{Resultados Quantitativos}

A pergunta de número um consiste em saber se os alunos possuem algum curso na área das TIC, o objetivo deste item é permitir o mapeamento dos alunos que possuem cursos formais que englobe o aprendizado formal das TIC fora do ambiente escolar. Para a configuração de resposta foi permitido apenas às escolhas "Sim" e "Não" como respostas, tendo sido esta a única pergunta de categoria quantitativa que não está na configuração da escala de Likert no modelo de cinco pontos.

De acordo com os resultados obtidos na entrevista, apenas $16 \%$ dos alunos possuíam algum curso em alguma área que compreende as TIC, enquanto que $84 \%$ não possuíam nenhum curso, mostrando assim que uma vez interrompidos os estudos iniciais, poucos são os alunos que realizaram cursos na área de tecnologia.

A pergunta de número dois tem por objetivo permitir com que os alunos possam auto avaliarem seus domínios nas TIC, cabe aqui salientar que embora muitos não tenham cursos formais na área das TIC, conforme evidenciado nos resultados da subseção anterior, isso não necessariamente significa que eles não possam ter $o$ domínio nessas tecnologias, uma vez que a tecnologia está inserida no dia a dia, há de se considerar os conhecimentos aprendidos por eles ao longo da vida.

Conforme configuração da escala de Likert no modelo de cinco pontos, esta pergunta possui cinco pontos para as respostas, onde: i) As respostas "Muito Ruim" e "Ruim" fazem parte do espectro negativo de resposta para a pergunta; ii) A resposta "Razoável" corresponde a neutralidade de resposta; iii) As respostas "Bom" e "Muito Bom" correspondem ao espectro positivo de resposta para a pergunta.

Os dados quantitativos de como esses alunos auto avaliaram seus domínios nas TIC mostraram que 3\% responderam que seu domínio era muito ruim, 3\% responderam que seu domínio era ruim, 34\% responderam que seu domínio era razoável, 38\% consideraram seu domínio como bom e $22 \%$ muito bom. Dessa forma, $60 \%$ dos entrevistados apresentaram respostas positivas em relação ao seu domínio nas TIC, $34 \%$ se mantiveram na neutralidade da pergunta em questão, enquanto que apenas $6 \%$ dos entrevistados emitiram um parecer negativo em relação ao seu domínio no uso das TIC. A pergunta de número três permite os alunos fazerem uma avaliação de como os professores tem utilizados as TIC nas aulas, assim sendo, podemos então avaliar o quanto esses profissionais tem buscado realizar a integração das tecnologias atuais nas salas de aula. Esta pergunta possui a seguinte configuração de concordância: i) As respostas "Não Utilizam" e "Utilizam com pouca frequência" fazem parte do espectro negativo de resposta; ii) A resposta "Utilizam ocasionalmente" faz parte da 
neutralidade de resposta; iii) As respostas "Utilizam com Frequência" e "Utilizam com Bastante Frequência" fazem parte do espectro positivo de resposta para a pergunta em questão.

Os resultados na visão dos alunos de como os professores têm utilizado as TIC em suas aulas foram que: i) $10 \%$ dos professores não utilizam; ii) $56 \%$ utilizam com pouca frequência; iii) $25 \%$ utilizam ocasionalmente; iv) $0 \%$ utilizam com frequência; v) $9 \%$ utilizam com muita frequência. Nessa pergunta em questão $66 \%$ dos entrevistados apresentaram respostas no espectro negativo no que se refere ao uso das TIC pelos professores na sala de aula, enquanto que $25 \%$ se mantiveram na neutralidade da pergunta em questão, e apenas $9 \%$ dos entrevistados emitiram um parecer positivo em relação ao uso das TIC pelos professores.

A pergunta de número quatro diz respeito à expectativa discente da geração de mais possibilidade no ensino mediante uso das TIC, vale salientar que esses alunos possuem expectativas e anseios diferentes dos alunos habituais que estão estudando na idade própria, assim sendo, eles compreendem que com o uso das tecnologias na sala de aula, pode-se mudar completamente a configuração da aula, permitindo maior autonomia e liberdade de pesquisa no qual não seria permitido no modelo mais tradicional de ensino.

Esta pergunta possui a seguinte configuração de concordância, onde: i) As respostas "Não gera mais possibilidade no ensino" e "Gera mais possibilidade no ensino de maneira razoável" fazem parte do espectro negativo; ii) A resposta "Gera mais possibilidades no ensino de maneira moderada" faz parte da neutralidade; iii) As respostas "Gera mais possibilidades no ensino de maneira significativa" e "Gera mais possibilidades no ensino de maneira bastante significativa" fazem parte do espectro positivo de resposta para a pergunta em questão.

Os resultados na visão dos alunos acerca da geração de mais possibilidades no ensino mediante o uso das TIC na sala de aula mostraram que: i) $0 \%$ dos entrevistados consideram que as TIC não geram possibilidades no ensino; ii) 19\% dos entrevistados consideram que as TIC geram possibilidades de maneira razoável no ensino; iii) $9 \%$ dos entrevistados consideram que as TIC geram possibilidades de maneira moderada no ensino; iv) $16 \%$ dos entrevistados consideram que as TIC geram possibilidades de maneira significativa no ensino; v) $56 \%$ dos entrevistados consideram que as TIC geram possibilidades de maneira bastante significativa no ensino.

De acordo com os dados respondidos para esse questionamento, $72 \%$ dos entrevistados emitiram um parecer positivo acerca da geração de mais possibilidades no ensino mediante uso das TIC, 9\% dos entrevistados se mantiveram na neutralidade da pergunta em questão, e 19\% dos entrevistados emitiram um parecer cético acerca da geração de novas possibilidades mediante uso das TIC no ensino.

\subsection{Resultados Qualitativos}

A última pergunta do formulário de pesquisa permite com que o aluno possa dissertar acerca de suas considerações sobre como as TIC tem os ajudados no aprendizado. Com o objetivo de preservar os nomes dos entrevistados, conforme ética de pesquisa, iremos utilizar o termo "Entrevistado 1, Entrevistado 2" e assim por diante. A seguir serão expostas as considerações de sete dos trinta e dois entrevistados, os textos receberam correções ortográficas, porém, sendo preservado seu real sentido. 
O Entrevistado 1 considera que: "(as TIC) tem me ajudado muito com as pesquisas nas tarefas de trabalho". O Entrevistado 2 afirma que: "Sim! Com o auxílio das TIC podemos alcançar um melhor rendimento em sala de aula, pois com o uso das TIC podemos realizar pesquisas e fazermos trabalhos escolares. Também podemos compartilhar nossos conhecimentos."

O Entrevistado 3 diz: "Hoje, eu gosto muito de fazer pesquisa no celular, no computador, e me ajuda muito." O Entrevistado 4 pondera que: "Sim. Através do celular tem me ajudado muito sobre pesquisa. Portanto, tendo como trabalhar mais nas salas de aula seria melhor". O Entrevistado 5 opina que: "Sim, ajudou bastante. Utilizada de maneira orientada representa o futuro do aprendizado dos alunos e o dia a dia dos professores".

O Entrevistado 6 afirma que: "Sim. Porque é muito importante, já recebi muito ajuda nessa área até porque eu não tenho curso de nem uma área das TIC". O Entrevistado 7 pondera que: "Tem me ajudado muito, o que eu não consigo acompanhar na sala de aula, eu acho na internet. Eu acharia que ajudaria muito as TIC na sala de aula, como um trabalho em sala de aula, em alguma dúvida, ou em várias coisas."

\section{Considerações Finais}

Partindo de uma perspectiva temática da pedagogia libertadora na qual esta deve ser forjada com o próprio oprimido (FREIRE, 2019) ao passo que na realidade, ainda persistem as situações da exclusão da participação do discente na definição da metodologia de ensino dos professores, realizamos um estudo exploratório da expectativa dos discentes EJA no uso das TIC no ensino da escola Joaquim Rosal Sobrinho, na cidade de Bom Jesus-PI, onde foi possível a constatação dos seguintes fatos.

Fato 1 - A maioria dos alunos possuem conhecimento prévio acerca das TIC que possibilita seu o uso na sala de aula como ferramenta auxiliar no ensino. Fato 2 - O uso das TIC na sala de aula podem atuar como complemento no aprendizado tecnológicos daqueles que não dominam algumas dessas tecnologias. Fato 3 - Caso o professor venha fazer uso das TIC no ensino, este dispõe de aprovação e boas expectativas por parte dos estudantes. Fato 4 - Muito embora os professores possuam a aprovação dos alunos para o uso das TIC em sala de aula, estes não tem feito uso desses recursos frequentemente no ensino EJA da Unidade Escolar que foi utilizada como objeto de estudo neste trabalho.

Dentre as contribuições desse estudo, podemos citar a exposição das considerações dos discentes EJA acerca do uso das TIC no ensino, para que por meio disso, suas expectativas sejam levadas em conta na hora do planejamento didático pelo professor, uma vez que, a transformação dos campos da sociedade deve acontecer com a participação de todos. Como trabalhos futuros, sugerimos o estudo a nível docente e gestor do porquê as TIC não tem sido frequentemente utilizadas no ensino, muito embora, tenhamos a aprovação e boa expectativa discente quanto a isso.

\section{Referências Bibliográficas}

ALCOFORADO, Luís; BARBOSA, Márcia Regina; BARRETO, Denise Aparecida Brito. Diálogos Freireanos: a educação e formação de jovens e adultos em Portugal e 
no Brasil. Imprensa da Universidade de Coimbra / Coimbra University Press, 2017.

BARACHO, Maria das Graças; NÓBILE, Vania do Carmo. A formação do educador nos aspectos técnico, ético e político para atuação em EJA integrada à EPT. Educação Profissional integrada à EJA do Curso de Especialização em Práticas Assertivas em Didática e Gestão da Educação Profissional integrada à Educação de Jovens e Adultos, 2019.

BRASIL. Lei $\mathbf{N}^{0}$ 9.394, de 20 de Dezembro de 1996. Disponível em< http://www.planalto.gov.br/ccivil_03/leis/L9394.htm> Acesso em: 01 de julho de 2021.

BRASIL. Lei $\mathbf{N}^{0}$ 13.632, de 06 de Março de 2018. Disponível em $<$ http://www.planalto.gov.br/ccivil_03/_Ato2015-2018/2018/Lei/L13632.htm\#art1> Acesso em: 02 de julho de 2021.

BRASIL. Ministério da Educação. Secretaria de Educação Profissional e Tecnológica: Programa de integração da educação profissional com a educação básica na modalidade Educação de jovens e adultos. PROEJA: Educação profissional técnica de nível médio/ensino médio: Documento Base. Brasília, DF, 2007.

DA FONSECA, Christine Meyrelles Felipe. A Didática e as Tendências Pedagógicas. Educação Profissional integrada à EJA do Curso de Especialização em Práticas Assertivas em Didática e Gestão da Educação Profissional integrada à Educação de Jovens e Adultos, 2019.

FLORES, Angelita Marçal. Educação mediada pelas tecnologias da informação e comunicação. Senac, 2018.

FREIRE, Paulo. A Pedagogia do Oprimido. Ed. São Paulo: Paz e Terra, 2019.

HUNG, Elías Said. Fatores associados ao nível de uso das TIC como ferramentas de ensino e aprendizagem nas escolas públicas do Brasil e da Colômbia. Universidad del Norte, 2015.

JOSHI, Ankur et al. Likert scale: Explored and explained. British Journal of Applied Science \& Technology, v. 7, n. 4, p. 396, 2015.

MERCADO, Luís Paulo Leopoldo. Formação continuada de professores e novas tecnologias. Maceió: EDUFAL, 1999.

MERCADO, Luís Paulo Leopoldo. Novas tecnologias na educação: reflexões sobre a prática. Maceió: EDUFAL, 2002.

MIRANDA, Guilhermina Lobato. Limites e possibilidades das TIC na educação. Sísifo, n. 3, p. 41-50/EN 39-48, 2016.

PERALTA, Helena; COSTA, Fernando Aluquerque. Competência e confiança dos professores no uso das TIC. Síntese de um estudo internacional. Sísifo, n. 3, p. 7786/EN 75-84, 2016.

VELOSO, Renato dos Santos. TECNOLOGIAS DA INFORMAÇÃO E DA COMUNICAÇÃO. Editora Saraiva, 2017. 